\title{
A Atuação da Tríplice Hélice em Santa Catarina pela Visão dos Núcleos de Inovação Tecnológica (NITs) do Estado
}

\author{
Cristiane lata Doutoranda em Engenharia e Gestão do Conhecimento. Universidade \\ Federal de Santa Catarina (UFSC) - Brasil. cristianeiata@hotmail.com \\ Cristiano José Castro de Doutor em Administração de Empresas. Universidade Federal de Santa \\ Almeida Cunha Catarina (UFSC)-Brasil. 01cunha@gmail.com
}

RESUMO

A atuação integrada entre universidade, indústria e governo contribui para o crescimento de uma região, pois cria um ambiente propício para que a inovação aconteça. O presente trabalho investigou, por meio de uma pesquisa qualitativa realizada em 2016, o nível de integração dos atores da tríplice hélice (governo, empresas e universidades) em Santa Catarina. A pesquisa foi realizada com seis coordenadores de NITs - Núcleo de Inovação Tecnológica. Os resultados mostram que cada uma das hélices tem trabalhado para se desenvolver, porém, a atuação ainda não acontece de maneira integrada. Uma preocupação apontada pelos entrevistados foi que qualquer modelo de atuação escolhido para a tríplice hélice no Estado deverá considerar as diferenças regionais existentes. Além disso, é preciso entender quais são os atores regionais de cada hélice e qual a melhor forma para que eles possam trabalhar de maneira integrada.

Palavras-chave: Tríplice Hélice. Inovação. Liderança. Interação Universidade-Empresas-Governo.

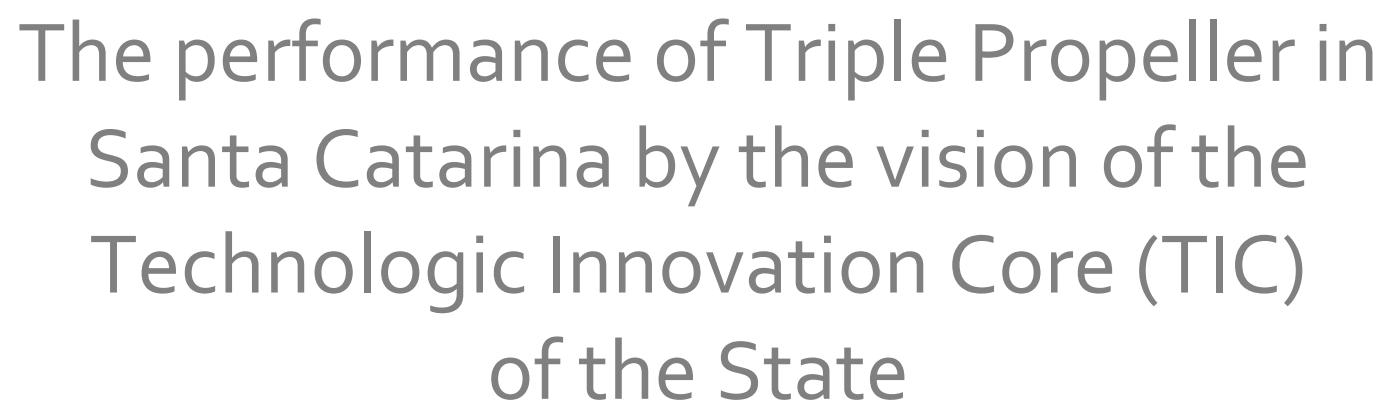

\begin{abstract}
The integrated action between university, industry and government contributes to the growth of a region, as it creates an enabling environment for innovation to take place. The present work investigated, through a qualitative research carried out in 2016, the level of integration of the actors of the triple propeller (government, companies and universities) in Santa Catarina. The research was carried out six coordinators of Tecnologic Innovation Cores (TIC). The results show that each of the propellers has worked to develop, however, the performance still does not happen in an integrated way. One concern pointed out by the interviewees was that any model of action chosen for the triple propeller in the State should consider the existing regional differences. In addition, you need to understand what the regional actors are about each propeller and how best they can work together.
\end{abstract}


Keywords: Triple Propeller. Innovation. Leadership. Integration between university-companies-government.

\section{INTRODUÇÃO}

De acordo com Etzkowitz e Leydesdorff (1995), no modelo da tríplice hélice, a interação universidade, indústria e governo é a chave para a inovação e o crescimento em uma economia baseada no conhecimento. O modelo da tríplice hélice se concretiza quando a tríade inicia um relacionamento mútuo, no qual cada ator contribui para aperfeiçoar o desempenho do outro (Etzkowitz, 2009). Essa dinâmica se constitui em um processo de colaboração entre os atores. Torna-se, portanto, importante explorar e entender a relação entre os atores de cada hélice.

A interação das hélices no Brasil foi regulamentada com a institucionalização da Lei de Inovação, em 2004, a partir da qual as ICTs (instituições científicas e tecnológicas) precisaram criar estruturas para gerir a sua política de inovação, gerenciar a propriedade intelectual e a transferência de tecnologia produzida na instituição. Essa estrutura recebeu o nome de Núcleo de Inovação Tecnológica - NIT.

De acordo com a Lei de Inovação, são competências mínimas do NIT:

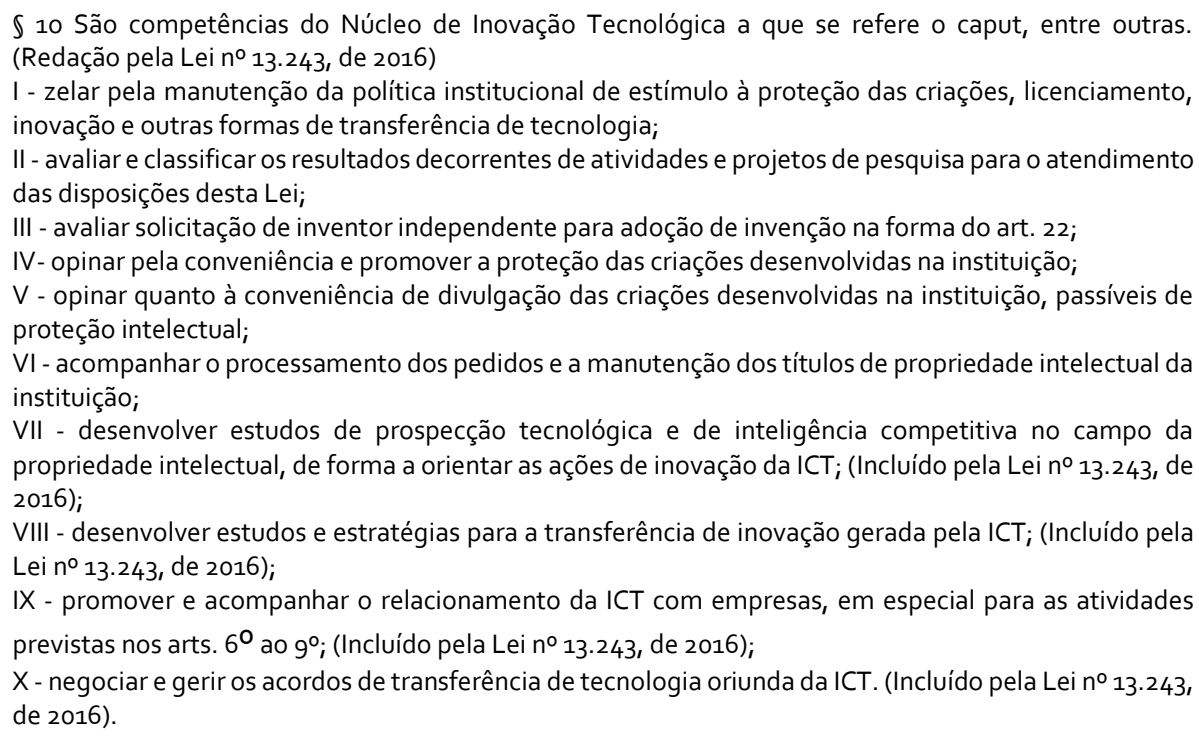

Pela importância dada aos NITs, a partir da Lei de Inovação, buscou-se por meio do presente trabalho investigar, pela visão de seus coordenadores, se as hélices governo, universidade e empresas atuam de maneira integrada em Santa Catarina.

\section{REVISÃO DA LITERATURA}

Os estudiosos continuam a encontrar na tríplice hélice um conceito útil para entender o sistema de produção de uma economia baseada no conhecimento (Khan \& Park, 2012).

Para os criadores do modelo, a universidade, o governo e a indústria devem atuar em sinergia de modo a fomentar a inovação. Em particular, a universidade atua como indutora nas relações com as indústrias e o governo de maneira ativa no desenvolvimento econômico via geração de conhecimento científico, tecnológico e inovação. Já o governo exerce um papel mais importante apenas quando uma atividade não pode ser provida 
pelo mercado (Etzkowitz, 2008). Os dois papéis importantes do governo são: 1) implementar políticas públicas que diminuam os entraves das relações na tríplice hélice; e 2) ser um agente fomentador de recursos, cada vez mais escassos tanto para a academia, quanto para as empresas. As empresas, por sua vez, atuam como produtoras de bens e serviços.

Apesar de definidos em um primeiro momento, os papéis de cada uma das hélices não devem ser vistos de maneira inflexível. Alguns estudos evidenciam que os papéis tradicionais de cada um dos atores na tríplice hélice tornaram-se mais permeáveis nos últimos anos. Ou seja, cada uma das hélices pode assumir o papel da outra (Etzkowitz; Carvalho de Mello, 2004; Etzkowitz; Leydesdorff, 2000; Etzkowitz et al., 1998). Isso está alinhado com o proposto por Geoghegan et al. (2015), onde a tríplice hélice é baseada em um modelo espiral de inovação, que permite que os três domínios institucionais (universidade - governo - indústria) interajam e compartilhem as relações mútuas com as três hélices.

Para Hira (2013), quando as hélices interagem tornam menos rígidos: 1) o vínculo de atividades de pesquisa com a academia; 2) a definição de políticas como atribuição única do governo; e 3) a produção com atividade exclusiva da indústria. $\mathrm{O}$ autor propõe que essas atividades podem ser realizadas por quaisquer dos atores - um laboratório público de pesquisa ou uma indústria liderando o processo de regulamentação. A universidade assume o papel da indústria ao estimular o desenvolvimento de novas empresas a partir das pesquisas, as empresas desenvolvem treinamentos e os governos agem como capitalistas públicos de joint venture (Etzkowitz, 2008).

Analisando as mudanças nos papéis das hélices ao longo do tempo, é possível perceber uma evolução na missão das universidades. Sua primeira missão estava centrada em repasse de conhecimento. A segunda missão possibilitou que as universidades se inserissem como atores do desenvolvimento econômico. Na chamada terceira missão das universidades encontra-se a principal mudança em termos de atuação das hélices. Espera-se cada vez mais das universidades a comercialização da pesquisa (Etzkowitz et al. 1998). As universidades estão assumindo o papel da indústria (produtivo) quando atuam como os principais intervenientes no processo de produção do conhecimento (Etzkowitz; Leydesdorff, 2000).

Confirma-se, portanto, que não há um papel definitivo para cada hélice. As sobreposições de atuação representam um aumento da flexibilidade das hélices e, como resultado, causam um impacto direto na geração da inovação.

Ao analisar as Lawton Smith e Bagchi-Sen (2010) chamam a atenção para o fato de que a presença ou ausência de um sistema de tríplice hélice, e se ele auxilia ou não as estruturas de inovação é uma função da qualidade do envolvimento de cada um dos três atores do modelo e de um determinado contexto geográfico, a sua disponibilidade de trabalho e infraestrutura social e física e sua posição dentro de sistemas mais amplos de inovação.

Portanto, investigar a atuação da tríplice hélice em uma determinada região pode contribuir para o entendimento do impacto que essa atuação tem na geração de inovação dessa região.

\section{METOdOLOGIA}

Para o presente trabalho, optou-se pelo método de pesquisa qualitativo e corrobora com o conceito dado por Creswell (2010), segundo o qual a pesquisa qualitativa é definida como um meio para explorar e para entender o significado que os indivíduos ou grupos atribuem a um problema social ou humano.

Optou-se por conversar com especialistas a fim de se obter mais conhecimento sobre a atuação da tríplice hélice em Santa Catarina. Foram realizadas entrevistas com seis coordenadores de NITs no Estado no ano de 2016. Tanto os NITs, quanto os seus respectivos coordenadores não serão identificados no presente trabalho. A figura 1 mostra as mesorregiões (IBGE - Instituto Brasileiro de Geografia e Estatística) do Estado onde estão localizadas NITs cujos coordenadores foram entrevistados. Algumas mesorregiões possuem mais de um NIT. 


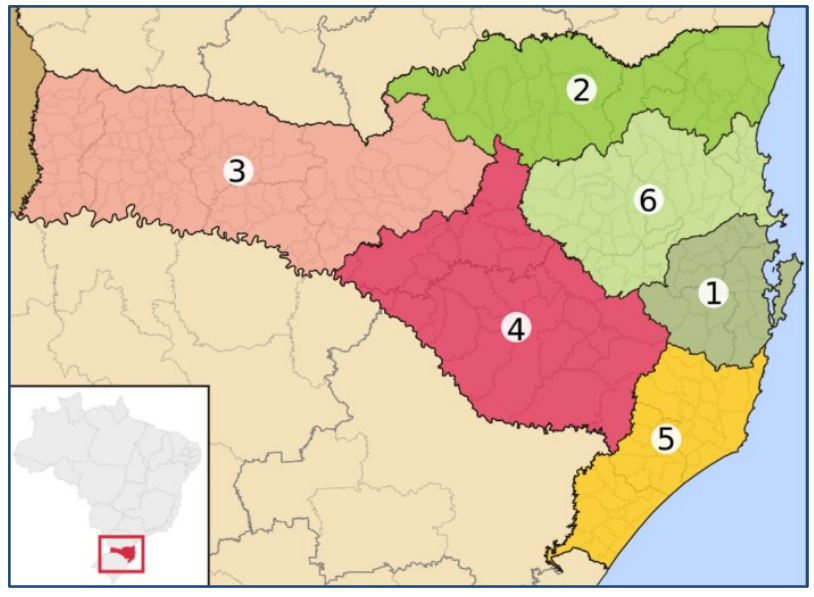

\begin{tabular}{|cl|c|}
\hline Mesorregião & $\begin{array}{c}\text { Possui NIT } \\
\text { respondente? }\end{array}$ \\
\hline 1. & Grande Florianópolis & $\operatorname{sim}$ \\
\hline 2. & Norte Catarinense & $\operatorname{sim}$ \\
\hline 3. & Oeste Catarinense & $\operatorname{sim}$ \\
\hline 4. & Serrana & não \\
\hline 5. & Sul Catarinense & não \\
\hline 6. & Vale do Itajaí & sim \\
\hline
\end{tabular}

Figura 1. Mesorregiões do Estado de Santa Catarina $x$ NITs respondentes Fonte: Elaborado pelos autores (2018).

As entrevistas foram semiestruturadas para garantir que as mesmas questões seriam respondidas em cada uma delas e ainda assim permitir tópicos emergentes durante o processo.

O quadro 1 a seguir apresenta as questões que ajudaram a nortear o desenvolvimento da entrevista semiestruturada.

\begin{tabular}{|c|c|}
\hline Sobre o entrevistado & $\begin{array}{l}\text { - Há quanto tempo você atua nesta área? } \\
\text { - Qual a sua experiência em projetos } \\
\text { interinstitucionais? }\end{array}$ \\
\hline Sobre a tríplice hélice & $\begin{array}{l}\text { - } \quad \text { Qual a sua visão sobre a tríplice hélice em SC? } \\
\text { - } \quad \text { Como ela funciona em SC? } \\
\text { - } \quad \text { Na sua opinião ela atua de forma } \\
\text { - } \quad \text { Quem fomenticulada/integrada? } \\
\quad \text { ator/instituição de articuladora da rede? }\end{array}$ \\
\hline Cenário do SIM - sistema articulado & $\begin{array}{l}\text { - } \quad \text { Parte de quem ou do quê? } \\
\text { - } \quad \text { Como esse sistema articulado funciona? } \\
\text { - } \quad \text { Como os atores interagem? } \\
\text { - } \quad \text { Está formalizado? } \\
\text { - } \quad \text { Quais ações são realizadas que demonstram a } \\
\text { - } \quad \text { atuação em rede? } \\
\text { - } \quad \text { Questão para fechamento: Como você vê a evolução } \\
\quad \text { desta interação no longo prazo? }\end{array}$ \\
\hline $\begin{array}{l}\text { Cenário NÃO - } \\
\text { sistema não atua articulado }\end{array}$ & $\begin{array}{l}\text { - } \quad \text { Você acredita ser importante o sistema trabalhar } \\
\text { - } \quad \text { Como ele deveria funcionar? } \\
\text { - } \quad \text { Partiria de quem ou do quê? } \\
\text { - Como seriam as interações? }\end{array}$ \\
\hline
\end{tabular}




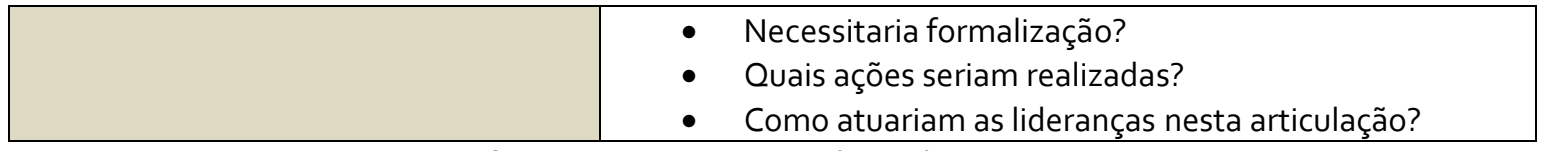

Quadro 1 - Questões norteadoras das entrevistas

Fonte: Elaborado pelos autores (2018)

Quatro entrevistas foram realizadas pessoalmente e duas delas, por solicitação dos entrevistados, foram realizadas por videoconferência. Todas as entrevistas foram gravadas, transcritas e, posteriormente, analisadas.

O trabalho contemplou apenas a visão de uma das hélices, correspondente à universidade e representada pelos NITs. As demais hélices (governo e empresas) não fizeram parte do presente escopo e devem ser investigadas em trabalhos futuros.

\section{RESULTADOS}

Nas seções a seguir, são apresentados os principais resultados coletados a partir das entrevistas com os coordenadores dos NITs sobre a atuação da tríplice hélice em Santa Catarina.

\subsection{O Início das Interações Universidade-Empresa: A Relação Pesquisador-Empresa}

Sobre suas experiências e atuação em projetos envolvendo outras instituições, os coordenadores entrevistados relataram as experiências principalmente quando a relação das universidades com as empresas era feita somente por meio dos seus pesquisadores. Em campos como as engenharias, o pesquisador tem a necessidade de aliar teoria e prática. Uma forma de fazer isso acontecer é por meio de projetos em parceria com empresas. O pesquisador entrava com a ideia de um projeto de inovação e a empresa com a estrutura necessária para a realização desse projeto. Em outros momentos, as empresas também acionavam os pesquisadores para atendimento as suas demandas de inovação. Era uma relação direta pesquisador-empresa.

Porém, essa relação apresentou algumas desvantagens. Um ponto em comum entre os entrevistados foi a menção da falta de regras claras, principalmente na questão da propriedade intelectual. O pesquisador preocupava-se em desenvolver o projeto e não com a gestão da relação universidade-empresa. Sem regras estabelecidas, muitas vezes, a universidade não tinha controle sobre os desenvolvimentos que estavam ocorrendo, nem sobre a qualidade do que estava sendo entregue ao setor produtivo. O que regia as relações era a necessidade algumas vezes da empresa, outras vezes do pesquisador.

Um dos entrevistados mencionou que a atuação em rede se apresenta de maneira mais forte entre os próprios pesquisadores do que entre os pesquisadores e as empresas. Eles articulam a formação de grupos de pesquisa para atender a uma demanda; trocam informações e dividem equipamentos quando necessitam de uma infraestrutura que não está disponível na sua universidade.

As experiências com projetos de inovação envolvendo outras instituições foram relatadas, em sua maioria, a partir de 2004. O provável motivo disso, está no fato de que a Lei da Inovação data desse ano. Com a institucionalização da Lei de Inovação, as ICTs precisaram criar estruturas, denominadas NITs - Núcleo de Inovação Tecnológica, para gerir a sua política de inovação, gerenciar a propriedade intelectual e a transferência de tecnologia. O que se percebeu na prática é fundamentado por Torkomian (2009) ao mencionar que o início das preocupações das ICTs com o tema inovação pode decorrer de um processo de desenvolvimento e amadurecimento institucional ou simplesmente para atender ao disposto na lei.

Os entrevistados relataram que no início, para o atendimento à legislação, os NITs foram transformados em escritórios de patentes. Porém, o papel de um NIT vai muito além da gestão de patentes nas relações com empresas. Com o passar do tempo, tem ocorrido um melhor entendimento dos papéis e, consequentemente, o amadurecimento das relações entre as instituições. Os pesquisadores, que antes eram os responsáveis pela relação com as empresas, passaram a contribuir para a adoção de práticas para regulamentar 
essa relação. Alguns dos coordenadores entrevistados vivenciaram o dia a dia como pesquisadores e possuem uma visão do que deu certo e o que precisa ser melhorado na relação universidade, empresa e governo.

\subsection{Relação Universidade-Empresa por Meio dos NITs}

Após a lei de inovação e com a evolução da maturidade da relação universidade-empresa, as próprias empresas começaram a exigir a formalização dessa relação. Algumas práticas foram adotadas para que essa relação fosse benéfica tanto para a universidade, quanto para as empresas. Os coordenadores entrevistados relataram algumas dessas práticas, a saber:

- Criação de um núcleo de projetos que capta recursos. Trata-se de um núcleo especializado na avaliação de editais e na disseminação desses editais dentro e fora da universidade. O núcleo também auxilia a estruturar os projetos de inovação para captação de recursos para as empresas;

- Participação em projetos em conjunto com outras instituições para atender às demandas de empresas de menor porte;

- Participação em editais de educação empreendedora para fomentar o empreendedorismo dentro da universidade e ajudar a criar os futuros empresários;

- Estreitamento da relação com gestor de inovação das grandes empresas e com associações de empresas do município;

- Estabelecimento dos objetivos do NIT para além da gestão propriedade intelectual, incluindo também a gestão da política de inovação e da transferência tecnológica;

- Realização de seminários, palestras, mesas redondas para aproximar as empresas da universidade e discutir o papel da tríplice hélice;

- Criação de cursos de pós-graduação para alunos que estão trabalhando nas empresas;

- Subsídio de projetos de desenvolvimento para empresa com recursos da própria universidade (fundos de pesquisa e extensão);

- Incubação de empresas e criação de parques tecnológicos dentro das universidades;

- Presença de professores nas discussões sobre a lei de inovação para o município;

- Criação de um espaço do empreendedor para facilitar a abertura de empresas;

- Auxílio no desenvolvimento de startup para atrair a atenção das grandes empresas;

- Divulgação internamente do que é o papel do NIT e como deve funcionar a interação universidade-empresa.

\subsection{O Papel das Universidades e o Papel do Governo}

Nas entrevistas realizadas não foi observado um ponto em comum quando os coordenadores mencionaram o papel das universidades. Houve relatos reforçando que a universidade ainda possui um papel muito acadêmico, distante da realidade do meio produtivo, o que dificulta a interação com as empresas.

Uma outra crítica apontada foi de que, quando se trata de desenvolvimento de pesquisa de ponta, isso acaba ficando restrito às universidades federais.

Em um dos NITs, o coordenador relatou que estão trabalhando fortemente na formação das pessoas de acordo com o que é demandado pelas empresas que atuam no entorno. E que quando as empresas se instalam em um parque tecnológico próximo a um NIT, esse ambiente torna-se favorável para a relação. Esse mesmo coordenador ressaltou que a universidade exerce seu papel empreendedor (universidade empreendedora) ao realizar processos de transferência tecnológica e ao formar empreendedores para a comunidade na qual está inserida.

Em relação ao papel do governo, a maior parte dos coordenadores mencionou o fomento à inovação. Os entrevistados concordam com o fato de que o governo deva ser a instituição fomentadora da inovação, pois 
sem recursos, não há como as hélices trabalharem de maneira articulada. As linhas de fomento seriam o agente motivador e propulsor para que realmente exista uma rede integrada no Estado.

As grandes empresas talvez consigam inovar com recursos próprios, mas em tempos de crise, empresas de menor porte não o farão por causa do seu alto custo e alto risco. A necessidade de linhas de fomento não reembolsáveis, por exemplo, foram apontadas como alternativas para que essas empresas possam investir em inovação, tendo as universidades como parceiras.

Foi ressaltado que mesmo que o governo disponibilize linhas de fomento, é necessário que as empresas acessem essas linhas sem tanta burocracia. Muitas delas não usufruirão do fomento se entenderem que os mecanismos são complexos tanto para solicitação, quanto para a prestação de contas aos organismos financiadores após a utilização dos recursos.

Um dos coordenadores reforçou a necessidade de criação de políticas públicas com editais específicos que favorecessem a interação universidade-empresa. Por meio dessas políticas públicas é que as ações poderiam ser articuladas. Ela seria um meio de ação enquanto a iniciativa privada não consegue perceber que a pesquisa é fundamental para o seu desenvolvimento.

O governo também foi apontado por um dos coordenadores como a hélice que tem a visão sistêmica e, portanto, contribuiria para entender como os atores poderiam agir de maneira integrada.

\subsection{Atuação da Tríplice Hélice em Santa Catarina}

Ao serem questionados sobre a atuação integrada da tríplice hélice em Santa Catarina, todos os coordenadores responderam que isso ainda não é uma realidade no Estado. Um dos coordenadores deu uma visão sobre o modelo americano de atuação da tríplice hélice em comparação ao modelo francês. Ele ressaltou que tendemos a copiar o modelo americano, quando na verdade nosso sistema educacional está muito mais próximo do sistema francês, que é uma academia clássica e não uma universidade tecnológica.

Para esse coordenador, nos Estados Unidos, o modelo de atuação para inovação está muito mais voltado para a criação da próxima Google ou Facebook. No Brasil, a preocupação maior deveria ser com o aumento do nível de vida e da qualidade da inovação com pequenas, médias e grandes empresas. O horizonte não deveria "ser uma Google", mas sim poder ter um bom salário, dar emprego para as outras pessoas na sua cidade, seu grupo, seu bairro.

A segunda escolha mencionada como modelo escolhido pelo Brasil foi a Espanha. Porém, alguns entrevistados relataram que a Espanha investiu muito recurso em estruturar seu modelo de atuação, porém, não cobrou o cumprimento de metas. Por isso, esse modelo também não serviria para o Brasil.

Países como Suécia e Finlândia foram citados pelos entrevistados como bons modelos de atuação da tríplice hélice. Eles possuem fomento para inovação incentivado pelo governo e pelas empresas e contemplam no seu desenvolvimento uma quarta hélice que é a sociedade. São investidos recursos públicos, recursos das empresas e a sociedade é chamada para discutir qual é a prioridade para a região. A escola de tecnologia superior de Montreal e a PUC do Rio Grande do Sul também foram mencionadas como instituições referência na interação universidade-empresa.

Foi ressaltado pelos coordenadores que a lentidão do governo fez com que a sociedade se mobilizasse para fazer as coisas acontecerem. Muitas ações foram resultado de um movimento liderado pela sociedade e não pelo governo e talvez essa seja uma alternativa mais viável.

Os entrevistados demonstraram preocupação com o uso de modelo "prontos" de articulação das hélices sem que sejam observadas as diferenças regionais do Estado e que independente do modelo adotado, será preciso entender quais são os atores regionais de cada hélice e qual a melhor forma para que eles possam trabalhar de maneira integrada.

\subsection{Instituição Neutra}


Ao questionar se uma das hélices deveria liderar a atuação em rede, os coordenadores apontaram a necessidade de haver uma instituição neutra, ou seja, que não fosse parte integrante da tríplice hélice, para articular a relação entre essas hélices.

O IEL/SC - Instituto Euvaldo Lodi de Santa Catarina, entidade do Sistema FIESC - Federação das Indústrias do Estado de Santa Catarina, foi apontado como exemplo de uma instituição articuladora e interlocutora na relação universidade-empresa e na elaboração de projetos para captação de recursos em fontes financiadoras.

Além disso, foi apontado que a própria FIESC poderia estimular que as empresas de Santa Catarina abrissem editais específicos relacionados as suas demandas. Com isso, haveria menor dependência de fomento do governo.

\subsection{Centros de Inovação}

Com o objetivo de estimular a produção de tecnologia e conhecimento de regiões do Estado de Santa Catarina serão inaugurados 13 centros de inovação, conforme figura 2. (Observação: até a data do presente trabalho, apenas o centro de inovação de Lages tinha sido inaugurado).

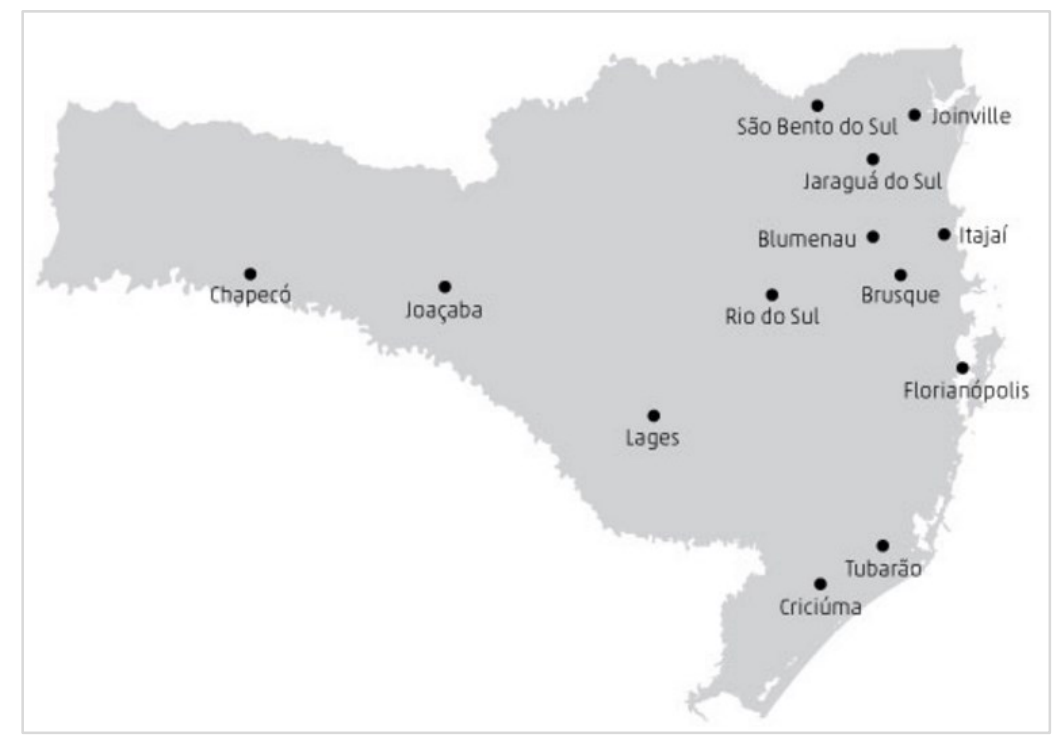

Figura 2. Localização dos centros de inovação em Santa Catarina

Os centros de inovação, para os entrevistados, tangibilizam a atuação da tríplice hélice em uma região. Dentro deles é preciso haver representante das três hélices trabalhando de maneira integrada pelo desenvolvimento da região. Caso contrário, serão somente prédios. Para os coordenadores dos NITs, a governança desses centros deve ser planejada. É preciso desenhar como esses atores vão trabalhar juntos e inserir a sociedade como parte interessada nesse planejamento.

De acordo com os respondentes, a liderança nos centros não deve ser exercida nem pelo Estado e nem pela universidade. Um dos respondentes mencionou mais uma vez que instituições neutras, como o IEL/SC, deveriam estar presentes nos centros para que os interesses de cada uma das hélices fossem garantidos e equilibrados. Em relação aos demais respondentes, nenhum deles mencionou qual seria o melhor modelo de atuação ou governança para os centros.

Os coordenadores apontaram ainda para o cuidado, mais uma vez, em não copiar o que funciona fora do Brasil. Em cada um dos centros, é necessário observar a questão cultural e a dinâmica da região, para então propor a melhor forma de atuação da tríplice hélice.

\section{CONSIDERAÇÕES FINAIS}


O presente trabalho investigou, por meio da visão dos NITs, se os atores da tríplice hélice (universidadeempresas-governo) em Santa Catarina atuam de maneira integrada.

Em um histórico da relação universidade-empresa, no início, as interações eram realizadas diretamente com os pesquisadores. Porém, sem regras claras estabelecidas para essa interação não havia controle sobre os desenvolvimentos que estavam ocorrendo, nem sobre a qualidade do que estava sendo entregue ao setor produtivo.

Com a Lei de Inovação, os NITs foram criados para fazer a gestão da política de inovação, da propriedade intelectual e da transferência de tecnologia e os pesquisadores puderam concentrar seus esforços nas pesquisas propriamente ditas e não mais na responsabilidade da parte burocrática da relação.

Ao abordarem o papel da hélice universidade, não foi evidenciado senso comum por parte dos entrevistados. Algumas críticas foram apontadas, tais como a distância existente entre a universidade e a realidade do meio produtivo e o fato de que a realização de pesquisas de ponta tem acontecido somente nas universidades federais. Apenas um coordenador apontou que estão trabalhando no desenvolvimento de pessoas para atender às demandas das empresas na sua região.

A hélice governo foi vista como a responsável pelo fomento à inovação. Mesmo assim, foi relatado que quando há muita burocracia, as empresas se retraem na busca pelos subsídios. Em alguns casos, a sociedade tem se mobilizado ao invés de esperar uma atuação do governo na região.

Cada uma das hélices tem trabalhado para se desenvolver, porém, esse desenvolvimento não está ocorrendo de maneira articulada. Pelas respostas dadas pelos coordenadores, observou-se que não há um modelo definido para ser implementado no Estado.

Uma preocupação apontada pelos entrevistados foi em relação a implementação de modelos de atuação da tríplice hélice sem que sejam consideradas as diferenças regionais do Estado e suas particularidades. Em cada região, é importante entender quem são os atores de cada uma das hélices e como eles podem se relacionar.

Países como Suécia e Finlândia foram citados pelos entrevistados como bons modelos de atuação da tríplice hélice por possuírem fomento para inovação incentivado pelo governo e pelas empresas e contemplarem no seu desenvolvimento uma quarta hélice que é a sociedade.

São recomendados estudos futuros com proposições de formas de atuação integrada para a tríplice hélice em Santa Catarina e pesquisas para entender a visão das demais hélices.

\section{REFERÊNCIAS}

Creswell, J. W. (2010). Projeto de pesquisa: Métodos qualitativo, quantitativo e misto. 3. ed. Porto Alegre: Artmed, 1227-1244.

Etzkowitz, H. (2009). Hélice Tríplice: universidade-indústria-governo inovação em movimento. Porto Alegre: EDIPUCRS, 207.

Etzkowitz, H. (2008). The Triple Helix: University-Industry-Government in Action, Routledge, New York.

Etzkowitz, H.; Carvalho de Mello, J. (2004). The rise of a triple helix culture: innovation in Brazilian economic and social development. International Journal of Technology Management and Sustainable Development, 2(3), 159171.

Etzkowitz, H.; Leydesdorff, L. (2000). The dynamics of innovation: from national systems and 'Mode 2' to a triple helix of university-industry-government relations. Research Policy, 29(2), 109-123.

Etzkowitz, H.; Leydesdorff, L. (1995). The Triple Helix University-industry-government relations: A laboratory for knowledge based economic development. EASST review, 14(1), 14-19.

Etzkowitz, H.; Webster, A; Healey, P. (1998). Capitalizing Knowledge: New Intersections of Industry and Academia. Albany, NY: State University of New York Press,

Geoghegan, W.; O'Kane, C.; Fitzgerald, C. (2015). Technology transfer offices as a nexus within the triple helix: the progression of the university's role. International Journal of Technology Management, 68(3), p. 255.

Hira, A. (2013). Mapping out the Triple Helix: how institutional coordination for competitiveness is achieved in the global wine industry. Prometheus, 31(4), 271-303.

Khan, G.; Park, H. (2012). Editorial: triple helix and innovation in Asia using scientometrics, webometrics, and informetrics, Scientometrics, 90(1), 1-7. 
Lawton Smith, H.; Bagchi-Sen, S. (2010). Triple Helix and regional development: a per- spective from Oxfordshire in the UK. Technology Analysis \& Strategic Management, 22(7), 805-18.

Maxwell, J. A. (2008). Designing a qualitative study. In: Bickman, L; Rog, D. (Ed.) Handbook of Applied Social Research Methods. Thousand Oaks CA: Sage, 214-253.

Merriam, S. B. (1998). Qualitative research and case study applications in education. San Francisco (CA): Jossey-Bass, 3-25.

Taylor, S. J. and Bogdan, R. (1997). Introduction to qualitative research methods: a guidebook and resource. 3. Ed. New York: John Wiley, 3-23.

TORKOMIAN, A. (2009). Panorama dos núcleos de inovação tecnológica no Brasil. In: Santos, Marli Elizabeth Ritter dos; Toledo, Patricia Tavares Magalhães de; Lotufo, Roberto de Alencar (Org.). Transferência de Tecnologia: Estratégias para a Estruturação e Gestão de Núcleos de Inovação Tecnológica. Campinas: Komedi, 21-39. 